This item was submitted to Loughborough's Research Repository by the author.

Items in Figshare are protected by copyright, with all rights reserved, unless otherwise indicated.

\title{
When will we learn? Improving lessons learned practice in construction
}

PLEASE CITE THE PUBLISHED VERSION

http://dx.doi.org/10.1016/j.jproman.2012.10.005

PUBLISHER

(c) Elsevier

VERSION

AM (Accepted Manuscript)

LICENCE

CC BY-NC-ND 4.0

REPOSITORY RECORD

Carrillo, Patricia M., Kirti Ruikar, and Paul A. Fuller. 2019. "When Will We Learn? Improving Lessons Learned Practice in Construction". figshare. https://hdl.handle.net/2134/11304. 
This item was submitted to Loughborough's Institutional Repository (https://dspace.lboro.ac.uk/) by the author and is made available under the following Creative Commons Licence conditions.

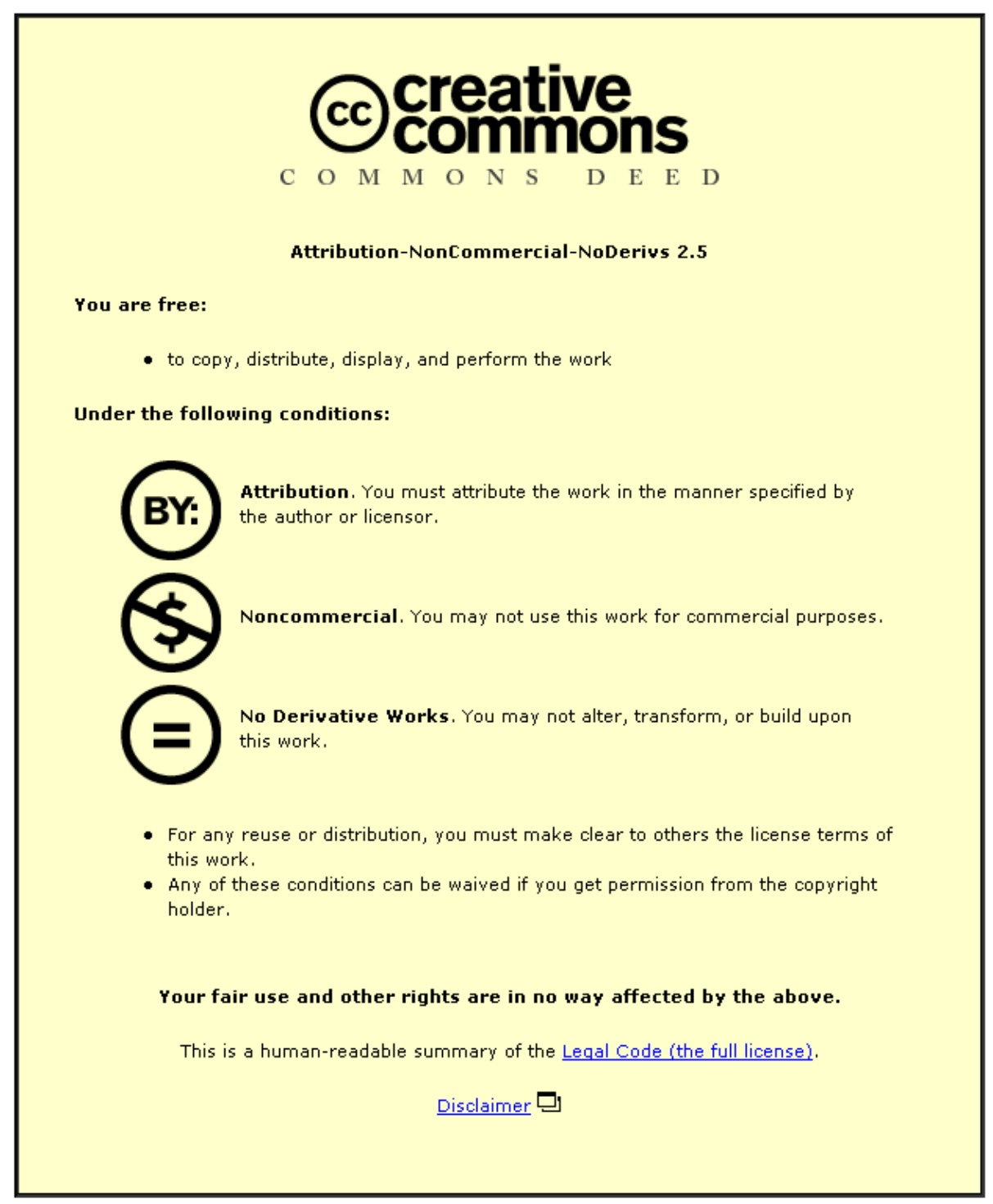

For the full text of this licence, please go to: http://creativecommons.org/licenses/by-nc-nd/2.5/ 


\title{
When Will We Learn? Improving lessons learned practice in construction
}

\author{
Patricia Carrillo ${ }^{1 *}$, Kirti Ruikar ${ }^{1}$ and Paul Fuller ${ }^{2}$ \\ ${ }^{1}$ School of Civil and Building Engineering, Loughborough University, Loughborough, \\ Leicestershire LE11 3TU, UK \\ ${ }^{2}$ DownerMouchel, Unit 13A, 1 Braid Street, Perth, Australia \\ *Corresponding author
}

\begin{abstract}
Purpose

The aim of the research is to improve lessons learned practices within construction contractor organisations. This will result in contractors' project teams having access to the most relevant lessons at the most appropriate time, in the most appropriate format.
\end{abstract}

\section{Scope}

The research was based on the responses of 41 large UK contractor organisations to a questionnaire survey, detailed interviews with nine companies and three focus groups. The respondents were senior and middle managers variously involved in business improvement, knowledge management, and technical services.

\section{Results}

The questionnaire survey identified methods, tools and processes used to collect lessons learned. The interviews and the focus groups uncovered the diverging requirements of corporate versus site-based staff. The data contributed to the development of a project learning model and a conceptual model from which a Project Learning Roadmap was derived to support business leaders to improve their project lessons learned processes. 
This will enable organisations to develop individual solutions tailored to stakeholders' needs.

Keywords: Construction, contractors, knowledge, lessons learned, roadmap 


\section{Introduction}

The UK construction industry is under ever increasing pressure from clients, both in the private and public sectors, to deliver projects faster, to better quality and lower cost (Egan, 1998 and Cabinet Office, 2011). The industry no longer has a choice on whether to adopt continuous improvement techniques and innovations that clients demand and write it into the contracts e.g. UK's Highways Agency Capability Assessment Toolkit (2011). In project-based environments, which are predominant in the construction sector, a common means of identifying improvements and innovations is through lessons learned activities. However, this has proved to be a difficult area in which to succeed (Carrillo, 2005; Udeaja et al., 2006 and Anbari et al., 2008). There are significant problems in the current economic climate in that lessons are often 'tacit' and held in peoples' 'heads' or 'minds' (Tsoukas, 2001; Nonaka and Takeuchi, 1995) and with reductions in workforces this learning or knowledge leaks away and is lost forever to the organisation unless it is captured and/or shared (Davenport et al., 2006). This demonstrates the importance of the social dimension to learning which Lave and Wenger (1991) described as 'situated' in social practice which influences how successful and difficult any learning is as the 'control' is within the individual as well as the organisational context. This means that the differing needs that can arise between those of the organisation and those of the individual need to be taken into account. Therefore, approaches to learning within projects may be different to those of learning across projects and in the wider organisation (Easterby-Smith, 2000). The guidance currently available concentrates on how to conduct lessons learned in terms of capture rather than the problem of dissemination and implementation of lessons (Collison and Parcell, 2001; Disterer, 2002; Schindler and Eppler, 2003 and Julian, 2008). In particular, the content, format and retrieval methods used can create problems for end users in project teams. 
This paper reports on the findings of a study aimed at developing an approach construction leaders could adopt to improve their lessons learned practices. The first part of the paper addresses the importance of learning and the construction project context. Next, the research method adopted is explained and justified. This is followed by a description of a conceptual model that translates into a Project Learning Roadmap. Finally, the limitations of the research and its Conclusions are presented.

\section{Importance of Lessons Learned}

Secchi et al. (1999) defined lessons learned as "A lesson learned is a knowledge or understanding gained by experience. The experience may be positive, as in a successful test or mission, or negative, as in a mishap or failure. Successes are also considered sources of lessons learned. A lesson must be significant in that it has a real or assumed impact on operations; valid in that is factually and technically correct; and applicable in that it identifies a specific design, process, or decision that reduces or eliminates the potential for failures and mishaps, or reinforces a positive result." This definition emphasises lessons can be positive or negative and that they must have impact.

Lessons learned are able to provide competitive advantage if used properly. They also overlap with the broader areas of knowledge management and organisational learning which helps promote innovation depending on the organisation's absorptive capacity (Cohen and Levinthal, 1990). Knowledge management is the identification, optimisation and active management of intellectual assets to create value, increase productivity and sustain competitive advantage (Webb, 1998). In this context, lessons learned are the intellectual assets used to create value based on past experience. Likewise, lessons learned 
contribute to the organisation learning agenda. Numerous authors have discussed the need for organisational learning such as Argyris and Schon (1978), Fiol and Lyles, (1985) and Senge (1993).

Previous studies (Fisher et al., 1998; Weber et al., 2000) identified that, in spite of significant investments in lessons systems, their ability to promote knowledge sharing is limited. One of the main problems with lessons learned is that although they exist as a key part of most, if not all methodologies, they are rarely successfully employed (Scott and Harris, 1998; Paranagamage et al., 2012). Lessons need to be contextualised as well as generalised otherwise their effectiveness is diminished and their currency devalued. These leads to lack of take up and from this the idea that the value of lessons might be measured in the number of times they are reapplied and, if possible, some monetary value related to the benefits accrued.

Although lessons learned are generated by and between individuals through social interaction (Lave and Wenger, 1991), most solutions are developed to meet corporate needs for wider dissemination rather than focussing on individual project members' needs. This may arise due to the corporate requirements for the lessons to be stored in a repository for future extraction and wider re-use.

Nonaka and Takeuchi's (1995) concepts of organisational knowledge creation and knowledge conversion introduce the notion of tacit and explicit knowledge. In recent years this work has been reviewed and extended in a number of papers on which Nonaka collaborated (Nonaka and Takeuchi, 1995; Von Krogh et al., 2012). The former describes tacit and explicit knowledge interacting along a continuum. The latter explored the role of 
leadership in organisational knowledge creation and their findings and framework are particularly relevant in construction project contexts. They propose a theoretical framework which takes into account centralised leadership (found in formal organisations) and distributed leadership which is found in more informal organisations which is characteristic of project-based organisations. Their framework covers "activities relating to context, knowledge assets, and the knowledge creation process at three leadership strata" (Von Krogh et al., 2012). These are described as the structural layer which hosts formal and structured processes, a core activity layer which is informal and where 'knowledge is created through direct contact and collaboration, and a conditional layer which has leadership activities to connect the informal and formal layers. If these are taken into consideration then different approaches can be used to meet the range of corporate and individual needs. They can also take into account needs based on the different stages of the overall project lifecycle.

\section{The Construction Organisation Context}

Previous research has focused on lessons learned in the project management context but little has been done in the specific area of construction organisations. Gibson et al. (2007) is one of the few; they undertook a study of lessons learned practices within US construction organisations and proposed a high level lessons learned process comprising collection, analysis and implementation. The authors suggested three key steps as follows: (1) Assess the current state of lessons learned program; (2) Establish a vision for the lessons learned program; and (3) Define a process for how the organisation will reach the vision. The key tenets of this body of work focus on the adoption of a Maturity Model Matrix. Related work by Paranagamage et al. (2012) attempted to understand why 
construction organisations conducted lessons learned, what they did and the problems experienced. They discovered problems with ownership of lessons learned and the lessons learned processes.

Most of the related work in construction has focused on the broader area of knowledge management; many of these resonate with lessons learned. The work of Robinson et al. (2005) emphasised the importance of the tacit/explicit dimension in construction organisations and the need for tools to address both the codification and personalisation perspectives. Tang et al. (2010) also compared aerospace and construction industries' approaches to codification and personalisation strategies. They highlighted the problem of information overload due to cheaper storage space and the ICT culture of "storing everything". Chen and Mohamed (2010) explored this theme further in a study of Hong Kong-based contractors and concluded that tacit knowledge is of greater strategic importance than explicit knowledge in relation to business performance. The barriers to effective knowledge management in a construction context have been discussed by several authors and these include lack of senior level support (Carrillo, 2004), the temporal nature of construction projects and teams leading to lack of continuity of staff and subsequent knowledge loss (Graham and Thomas, 2008), lack of standard processes between the different organisations involved in projects (Carrillo et al., 2004), and individuals' egos and reluctance to share knowledge due to defensive routines (Argyris 1992). Time pressures are commonly referred to in the literature and this can sometimes be due to individuals being involved in multiple projects (Disterer, 2002; Egbu et al., 2003; Senaratne and Sexton, 2008; Wiewiora 2009). 


\section{Research Methodology}

The study adopted a qualitative approach given the abstract nature of the main research topics i.e. knowledge management and learning which is common in studies of this type (Cresswell, 2009). Typically, data collection is carried out in the form of electronic surveys, interviews with individual practitioners and focus groups (Fellow and Liu, 2008). These are designed to provide rich data sets which researchers can analyse to find common themes and answers to hypotheses (Yin, 2003). The results can then be used inductively to develop theories and models.

In this study, the research was carried out in four stages as shown in Figure 1.

$<$ Insert Figure 1 here $>$

\subsection{Stage 1: Understand the Dynamics of Project Learning}

Stage 1 was undertaken in order to try and make more sense of the research in this field based on available literature. This attempts to take the key issues into account and explain the dynamics of learning in project settings.

\subsection{Stage 2: Understand Current Practices and Barriers}

This was obtained from three different data sources and included:

- Questionnaires;

- Interviews; and

- Focus Groups. 
The questionnaires were aimed at understanding how companies captured, stored and disseminated lessons learned. It also aimed to discover the content and format of what is recorded and the retrieval methods used. It also identified the problems experienced by end users when accessing lessons learned repositories and identified practices that could be used to overcome these difficulties. An electronic questionnaire survey was sent to 122 UK construction companies listed in the New Civil Engineer Contractors File 2010 (NCE, 2010). Forty-one responses were received which were analysed to identify the key issues. The respondents were middle managers variously involved in business improvement, knowledge management, value and quality assurance, procurement, technical services, etc. The key issues identified from the questionnaires were as follows:

- Reasons for conducting lessons learned;

- Lessons learned contents and methods used;

- Usefulness of the methods and tools used;

- Participants in lessons learned; and

- Access to lessons learned.

The second batch of data collected consisted of nine interviews. The aim of this was to obtain company perspectives on the lessons learned provision and explore the tacit/explicit dimensions of project learning. The interview questions covered:

- Current practices for conducting lessons learned; and

- Barriers and improvements for current practices.

The nine individuals were selected from the questionnaire responses; these consisted of respondents who had stated that they would be willing to participate in an interview. Their positions were Knowledge Managers, Business Development Managers, Chief Engineers, etc. The nine interviewees were thus able to provide a corporate perspective on lessons learned. 
The third batch of data came from three focus groups; these originated from three of the interviewees volunteering their site-based project teams for further investigation. Each focus group consisted of about five to seven individuals in positions such as Project Managers, Site Managers, and Site Agents.

In preparation for the interviews a summary of the company's questionnaire response was reviewed. The focus groups reviewed and debated a summary of both the questionnaire results and the interview results. This provided triangulation between the three data sources and provided the perspectives on lessons learned from those who were tasked to collect and use lessons learned.

\subsection{Stage 3 Conceptual Model Development}

Based on the content analysis of the data obtained in Stage 2, a conceptual model was proposed to improve the understanding of lessons learned and their dissemination. The model specifically attempted to include the key areas that should be covered whilst addressing the existing barriers and the improvements required.

\subsection{Stage 4 Roadmap Development}

The key issues identified in Stage 3 were further developed, with the addition of actions and checklists to address those actions. This was translated into a Project Learning Roadmap that could be used by organisations' leadership teams to improve lessons learned practices, regardless of organisation size. 


\section{Results and Discussion}

This section briefly summarises the results from each of the three research stages.

\subsection{Results of Questionnaire Responses}

Data was obtained from 41 responses to a questionnaire on lessons learned practices. Respondents were given a Likert scale of options obtained from literature and options to add other statements. A summary of the main findings is as follows:

The main reasons for conducting lessons learned are (1) to learn for similar projects in the future $(100 \%) ;(=1)$ to avoid making mistakes and repeat successes $(100 \%)$; and (2) to provide a competitive edge over other companies (96\%); and (3) to learn lessons for consecutive stages of on-going projects. Overall, the responses suggest a strong desire to learn lessons for every stage of a project lifecycle. The main types of content used are (1) Health and Safety issues (80\% responses); (2) Contract programme issues $(72 \%) ;(=2)$ Environmental issues (72\%); and (3) subcontractor procurement issues $(64 \%)$.

The results showed a wide variety of methods, tools and processes were in use (see Figure 2). Post Project Reviews and Face-to-Face meetings were found to be the most informative practices and were also considered the most useful. The least used and the least informative were Video Conferences. In addition, company Intranets/Extranets were one of the most commonly used tools. The most informative overall were Brainstorming and Technical Forums. One respondent stated "We have a problem in capturing and recording good ideas from informal brainstorming sessions”. These results appear to reflect the 'social' nature of knowledge i.e. interactive 'face-to-face' activities being 
favoured, the importance of project context, and the difficulty of retrieval of knowledge buried in Project Files.

$<$ Insert Figure 2 here $>$

The most common participants of lessons learned activity are project managers, contract managers and quantity surveyors. Other members peripheral to the project team such as commercial managers, design managers, health and safety managers and regional managers were the next group of people likely to be involved. Those members considered as external to the core project team such as business improvement managers, subcontractor representatives and client's representatives were less likely to participate in lessons learned activity. Respondents were also asked to identify the level of access to lessons learned. $67 \%$ stated that lessons learned are open to all, $27 \%$ stated access was limited to certain teams and $6 \%$ stated they had no access to lessons learned

\subsection{Results from Interviews}

Data from the nine interviews helped to determine how organisations recorded and disseminated lessons learned. The interviewees consisted of individuals based in the regional or head offices of construction contractor organisations with responsibility for lessons learned practices. These respondents were chosen to provide a view of what the leaders in the organisations considered was happening in the area of lessons learned and how they could be improved from a corporate perspective. Table 1 shows details of the interviewees' positions and the size of their organisations.

$<$ Insert Table 1 here $>$ 
All interviewees were very passionate about discussing lessons learned and recognised the need to improve. Interviewee $G$ stated they undertook lessons learned to improve efficiency by cutting out the learning curve. He stated "We are reinventing the wheel in every part of our business. Region $[x]$ will experience a difficulty and another office can experience the same problem”.

The interviews covered:

- Current practices for recording and disseminating lessons learned; and

- Barriers and Improvements for current process.

\subsubsection{Current Practices: Interviewees’ Perspectives}

An analysis of the interviews was carried out to determine the tools used in terms of the tacit/explicit dimensions of project learning; the results are shown in Table 2. The most popular tacit tools are Post Project Reviews (PPR) and Project Meetings followed by Contacting Individuals and Communities of Practice. The most common explicit activities are Project Review Files and Intranets. The least used tacit tools were Conferences/Training, Technical Forums and Brainstorming sessions. In the case of explicit tools the least used were Wikis, audit reports, defect avoidance and feedback systems.

$<$ Insert Table 2 here $>$

The most popular activities for both tacit and explicit knowledge sharing were those that are usually mandated in company procedures for carrying out projects i.e. post project 
reviews and project review files respectively. However, in analysing their usefulness, project review files were found to be low with the company intranet scoring highest in the explicit category. This brings into question the importance of accessibility and the possibility that knowledge about lessons learned becomes 'buried' in project files which are not easily accessible (Carrillo et al., 2011; Schindler and Eppler, 2003). The results also indicated that where lessons are documented, these are the least popular methods and also found to be the least useful by the population in this study. The most informative methods indicated were those involving face-to-face communication which echoes the view that knowledge creation and learning are essentially social activities as proposed by many of the leading authors in the field (Nonaka and Takeuchi, 1995; Wenger, 2004).

\subsubsection{Barriers to Current Practices: Interviewees’ Perspectives}

The barriers highlighted are multi-faceted. A summary of some of these are:

Process: Whilst many companies accept lesson learned are best done at project stage gates, there are still many that rely solely on the project's completion to generate lessons learned. This means that many key project staff are not available. Because of the time requirement, one company allows one member of staff to produce a project review, solely on his view, from which lessons are drawn. These lessons then remain within the region and are not shared externally. Another company had a contractual requirement to produce an agreed number Best Practice sheets each month. This meant staff were pressured into generating more quantity than quality.

Reluctance to obtain external advice: Several interviewees described the reluctance to accept help from others; not wanting to share their problems or not willing to learn from other people's mistakes. Some Project Managers were not interested in documenting 
lesson learned because it reflected poorly on them. There is also an ingrained culture of looking forward to new projects, not back to completed projects.

Duplication of Workload: Interviewee I stated a lot of the lessons learned already exist in numerous other reports, but in a different format because they are required for a different audience, the typically management board. Site staff therefore resent the extra administrative burden of having to produce similar information in a different format for a different audience.

Lack of Perceived Value: Companies do not always recognise the value of lessons learned and in some cases only do them when requested by clients. In other cases, extra overheads are needed to police staff to do the lessons learned. Also, there are no formal processes to encourage new teams to consult previous lessons learned. Interviewee $\mathrm{H}$ was convinced that lessons learned are project-specific. In his view, only repeat projects could benefit from lessons learned. This means there is little enthusiasm to invest time and expenditure for reviews that are seen to have little value.

Internal Competition: Interviewees $\mathrm{A}$ and $\mathrm{G}$ cited internal competition as a key barrier to sharing lessons. One business unit would never ask another business unit for advice or help. It also means that failures are never discussed.

Legal Issues: Interviewee E's legal department had advised them to word lessons learned very carefully. They were not allowed to identify causes of problems because of the potentially negative consequences of using the UK's Data Protection Act. This means that there is no record that thoroughly reflects the lessons learned context.

Generally, the interviewees felt their companies have provided a wide range of corporate tools for capturing lessons learned. However, they acknowledged that their processes are not enforced and they still have a long way to go in finding the best way of communicating 
those lessons learned with their employees. This is where the next set of data is relevant. It highlights the needs of the site-based project teams and their views of the corporate systems provided.

\subsection{Results from Focus Groups}

The three focus groups were volunteered from companies A, F and G. The focus groups consisted of site staff views and covered:

- $\quad$ Current lessons learned practices; and

- $\quad$ Barriers and improvements for lessons learned practices.

It was important to obtain the views of the site staff to compare with the corporate view obtained from the nine individual interviews.

\subsubsection{Current Practices: Focus Groups’ Perspectives}

Personal Interaction: The three focus group participants were very strongly in support of the need to learn lessons, not by the use of ICT systems, but using personal interaction such as speaking to more experienced personnel or via team meetings. For example, all three groups had staff who had visited similar projects before commencing on site to learn about the project. Junior staff were comfortable about learning from more experienced members if they had previously met; they would not wish to contact someone that did not know or post questions on various ICT forums. Although company ICT systems, mainly the intranet, were not highly regarded, two of the groups mentioned Google was a greater source of information, once they knew what they were looking for. Thus, even though there are a range of ICT systems that are available to support the different knowledge management (KM) processes, it was found that most participants resorted to learning from doing. This finding is hardly surprising, given that such techniques are affordable, effective 
and direct. Often specialist KM ICT systems are dependent on investments in ICT infrastructure, require training and buy-in. Besides, there is a level of scepticism associated with technology adoption, especially in construction companies, which could be attributed to the fact that there is a general lack of understanding of the potential benefits of KM technologies. Most organisations view technologies as a means to an end and are therefore reluctant to invest in specialist KM ICT systems. These findings are consistent with the findings of a previous study by Ruikar et al. (2007).

Ad hoc use of tools: Two of the three participants agreed they knew about the range of lessons learning initiatives available, provided by the head office teams, but those tools were not used and there was no enforcement. For instance, one company had lessons learned cards and Activity Sheets for disseminating lessons but staff preferred to circulate emails amongst the project team because this was considered a simpler, more transparent process.

Communication of results: Two groups were aware of lessons learned sessions undertaken by senior management but they were disappointed that none of this filtered down to the site staff. In addition, there was the perception that these sessions were heavily focused on high-level commercial issues not on site-based issues. Instead, teams depended on key staff such Contracts Manager (who had an overview of multiple projects) to disseminate any lessons learned informally; they were the link between site teams and the head office. This was done in an ad hoc manner because the perception was that many Contract Managers would not want to highlight perceived failures.

\subsubsection{Barriers and Improvements: Focus Groups’ Perspectives}

These were numerous and a subset is described below. 
Inadequate communication: This is a major issue; it is twofold. Firstly, there is a difference between what the site teams see as useful and what the corporate systems demand. Two site teams were aware of only some of the facilities offered by the head office to promote lessons learned, the third was completely unaware. For example, what head office thought was useful was considered not relevant. Secondly, there is a lack of transparency in the outcome of some of the processes site team undertake e.g. completing a requisite number of lessons learned cards. These are considered to disappear into a "black hole"; they are aware that meetings occur at regional level but they are not party to the outcome. One suggestion is that these collations should at least be accessible to the project managers. Silo Environment: Site teams operate in a silo environment with little contact with other projects within their business units and have remote and tenuous links with the head/regional offices. They would highly value more opportunities to interact with other site teams who may have similar problems.

Little Value Added: The perception is that lessons learned documents provide little added value; site teams are being asked to generate documents but they see no evidence of them being useful and they do not have access to the outcomes.

Time Constraints: Site teams considered there to be few opportunities to share lessons. The expectation is that they get on with the job and everything else is peripheral. For this reason, any dissemination activity e.g. post project reviews only occur if forced.

Too Process Driven: Site Teams A and I thought their companies were process-driven, but in the wrong sense; it was more important to complete the correct documents and submit them in the right format than it was to have a look at the "big picture". Associated with this was the sense that head office staff should have a greater awareness of what was happening on site. 
Culture: This is manifested in a number of ways. Site team $\mathrm{G}$ was convinced that there needs to be a change in mind-set to encourage others to learn and to be willing to offer/take advice. "People do not like being told what they are doing is wrong so the sharing process falls down" (site team A). For site team F there is a culture of blame when things go wrong and the sense that some senior project managers believe "knowledge is power". There is also needs to be support from the senior management team to support learning. This is very detrimental in company $\mathrm{G}$ where competitiveness between business units means there is a disincentive to share learning. These findings resonate with Szulanski (1996) who investigated the "stickiness" of knowledge and tried to resolve the gap between what an organisation knows and what it puts to use. He used the term "stickiness" to describe the difficulty to transfer practice within a firm. Szulanski built on previous views which had assumed that stickiness was only affected by motivational factors such as lack of incentives, resistance to change, lack of commitment and lack of buy-in. His research showed that additional barriers include lack of absorptive capacity of the recipient (ability of the recipient to identify, value and apply new knowledge), causal ambiguity (the depth of the knowledge being transferred), and the arduous relationship between the source and the recipient (the ease of communication and closeness of the relationship). To overcome these barriers, Szulanski (1996, p37) recommended "it might be profitable instead to devote scarce resources and managerial attention to develop the learning capacities of organisational units, foster closer relationships between organisational units, and systematically understand and communicate practices". 
The above statements show that there is lot to be done to encourage site teams to adopt corporate lessons learned processes. Whilst none of these are new issues, it shows that organisations are yet to address these challenges. There is clearly a lack of communication and transparency between site teams and head-office teams that needs to be addressed. There is also a strong emphasis on people-to-people dissemination despite corporate office providing what they regard as a set of useful tools. Moreover, a culture of encouraging the collection and dissemination of lessons needs to be addressed. Time is always a factor but it masks the issue of site teams not recognising the value in collating lessons.

Table 3 summarises the data collected from the questionnaire, interviews and focus groups. The requirements of an improved lessons learned system is categorised to make sense of the findings. The five categories common to all three sets of data are:

- Needs - how can we collate lessons learned that are needed both for corporate metrics and well as site-based performance?

- Process and Tools - how can we overcome the ad hoc use of processes and encourage the use of tools that are useful and easy to administer?

- Content and Format - how can we collect lessons that are relevant and in a format that is easy to understand?

- Repository - how can we store lessons learned in manner that is easy to submit and retrieve?

- Communication and Dissemination - how can we alert those who need the lessons of their existence?

$<$ Insert Table 3 here $>$ 
Considering all the above factors, a Project Learning Roadmap was developed to provide further guidance.

\section{Project Learning Roadmap}

The conceptual model was translated into something that leaders in construction organisations can use to improve their project lessons learned processes and outcomes. Companies may need to address the questions of 'Do lessons learned address objectives at both project level and corporate levels?' 'Are the tools and techniques used appropriate?' 'Do our lessons learned processes address the problems they are designed to solve?'. The current lessons learned practices may not be geared to solve these problems, perhaps reflected in the desire for alternative tools and techniques. Rather than addressing these issues in a prescriptive manner, a Project Learning Roadmap is proposed (Figure 3). The Roadmap draws on the analysis of the interviews and focus groups (Table 3). The Roadmap consists of three main components as follows:

1. The Key Elements required to bring about change in the lessons learned practices;

2. The Actions that need to be undertaken by leaders at both corporate and project levels within the organisation; and

3. An Implementation Guide which provides supporting advice and information in the form of checklists from which each organisation could choose the best approach for their specific context and resultant needs.

$<$ Insert Figure 3 here $>$ 


\subsection{Key Elements}

These are expanded from the elements identified in Table 3. The aim of these are to identify the high level issues the organisations need to be address to improve the dissemination of lessons learned. The starting point is Preparation for the implementation of lessons learned. Most project planning literature advise a pre- planning phase to make any undertaking a success (Pinto and Prescott, 1990). The other five elements proposed are Needs Identification, Process and Tools Used, Content and Format of Lessons, Repository Used and Communication/Dissemination. The Key Elements also include a Review phase as proposed by both continuous improvement and learning literature. The aim of this is to ensure that the tasks undertaken address the aim of improving the collection and dissemination of lessons learned.

\subsection{Actions Required}

The central part of the Project Learning Roadmap itemises the various actions that need to be undertaken to address each Key Element. Von Zedwitz (2002, p. 255) lamented "most companies have not established a structured approach to learning from projects”. These Actions, in the form of a flow chart, are aimed at ensuring there is a structured and coherent manner to address the collection and dissemination of the lessons learned. Following Von Krogh et al. (2012) advice, it comprises two halves as a reminder that those activities are required to address both the corporate and project teams' needs. The data collection identified that these were sometimes at odds. This stage also contains two review tasks to ensure that the outcome delivers to the expectations. The detail of these will be discussed in the next section with reference to supporting documents. 


\subsection{Implementation Guide}

The Roadmap acts as the guide to implementing improved processes and is supplemented by a series of checklists aimed at providing practical advice for organisations (Table 4). The contents of the checklists were derived from the data collected from the interviews and focus groups. Where relevant, the checklists indicate whether the items are suitable for small and medium-sized organisations (SMEs) or large organisations. The European Commission's (2003) definition of SMEs (turnover less than €50m) was used.

\subsubsection{Preparation}

The aim of this item is to provide mechanisms to ensure that employees understand what lessons learned are, what they aim to do, the preferred ways lessons learned should collected, stored, disseminated and used.

\subsubsection{Needs Identification}

Von Krogh et al. (2012) highlighted the difference between corporate and individual needs. Section 4.5.1 also found both corporate and project staff needs should be addressed in any lessons learned system. Checklist 1 (Table 4) provides a sample of the areas that need to be considered for each group. The examples were derived from the questionnaire survey (corporate needs) and focus groups (project needs).

$<$ Insert Table 4 here $>$

\subsubsection{Processes and Tools}

Section 5.3.2 highlighted some of the project teams had little understanding of why they were collecting data stipulated why by head office as part their company's lessons learned 
system. This indicated the communication between the corporate office and the site-based team could be improved with regard to what they should do and why. In addition, Figure 2 highlighted the discrepancy in the perceived effectiveness of some tools used. This part of the Roadmap therefore focuses on the processes used within the organisations to collect lessons learned. Firstly the processes must be agreed by parties and secondly the tools required to deliver those processes should be those that are considered most useful. Checklist 2 (Table 4) provides sample tools and identifies their suitability based on different sizes organisation to address the scalability issue. Ruggles (1996), Anumba et al. (2005), and IDeA (2008) provide more in-depth discussion of relevant tools.

\subsubsection{Content and Format}

The capture of lessons learned in a format that is easily accessible is key to those lessons being re-used. The findings of the focus group showed project teams have difficulty in knowing what lessons learned are available. The A3 Thinking is adopted as a possible solution. The aim of the A3 report (Liker, 2003) is widely acknowledged as a simple format for problem solving. It includes an A3 sheet that is readily produced; it describes the problem, context, solution and review in a concise format (Shook 2008). In addition, Garon (2006) advises that if there are a large number of lessons learned a prioritisation should take place; the less significant ones could be made available to those who have the time to read them.

\subsubsection{Repository}

Section 5.2 highlighted $33 \%$ of the questionnaire respondents do not have access to lessons learned. One focus group stated “...after they [lessons learned cards] leave the site that the documents go into a 'black hole' without any use for anyone. In fact the knowledge 
area in the company intranet is also thought to be part of this black hole. No one knew where the lessons learned cards were or the activity sheets or the best practice sheets were." This problem therefore required an acknowledged place to store such lessons and how they may be retrieved. Checklist 4 therefore provides example storage and retrieval mechanism for lessons learned.

\subsubsection{Communication and Dissemination}

Communication of the lessons learned is important if learning is to occur. Quintas et al. (1997, p 387) highlighted the need to "ensure that everybody in the organization 'knows' where the knowledge is available within the organization.”. The focus groups highlighted they had little knowledge of what lesson there were. This is a challenge to address. Pushing lessons to users will lead to information overload and leaving it to staff to pull the lessons means that it rarely ever done. Checklist 5 provides some ideas on how lessons learned could be disseminated more effectively.

\subsubsection{Review}

Checklist 6 identifies mechanisms companies may use to judge the impact of their lessons learned. It requires metrics at both the site tam and corporate level. None of the data collection was able to provide evidence that companies undertook any reviews of their lessons learned processes.

It is envisaged that using the Project Learning Roadmap, with the support of the checklists, companies can tailor their lessons learned processes to maximise benefit. The Roadmap provides leaders with a tool to improve project learning in distributed leadership 
environments that exist in projects. This addresses the need to span the leadership strata outlined in the work of von Krogh et al. (2012).

Scalability is an overarching feature of the conceptual model. Lessons learned are equally important to small and large organisations. Thus any solutions proposed must be scalable to address the needs of all constituents. The tools used may vary considerably between organisation sizes due to the availability of resources available. For example, a study conducted by Williams (2008) indicated organisation size was considered a contributing factor to the type of lessons learned solution; he went on to emphasised there is no "one size fits all”.

\subsection{Validation of the Roadmap}

A workshop was held to validate the Roadmap proposed. The participants consisted of 19 professionals from a range of construction organisations including leading project management consultants, engineering design consultants, construction contractors and government agencies. The background of the research and its findings were presented; this was followed by proposed Roadmap. The main questions asked regarded the relevance of the Key Elements, The Actions required and Implementation Guide. All participants were in agreement that (1) current practices needed improvement; and (2) the Roadmap provided a structure that should improve on current practices. The main discussion surrounded whether the Roadmap's Actions should be more prescriptive. However, ensuing discussion supported the need for flexibility and scalability based on organisations' resources and culture. It was felt that using too a rigid structure would 
encourage employees to deviate from recommended practice. No recommendations were made for improving the Roadmap.

\section{Limitations to the Research Undertaken}

This study is considered to have three main limitations. Firstly, it was based on the UK construction industry and although some of the respondents are employed by multinational organisations, care should be taken in the use of the materials in contexts outside the UK without further validation of the applicability of the findings and tools proposed. Secondly, the interviewees were selected from respondents to the questionnaire. This means that random sampling was not used. Normally, this would mean that the responses could be biased. However, the responses from both populations indicated that there were differences in opinions between the two population samples. Thirdly, although the Project Learning Roadmap provides a structured approach, there is little guarantee that it will improve lessons learned without addressing other organisational issues such as culture, time and sense of value added.

\section{Conclusions}

This research was aimed at encouraging leaders in construction contractors to improve their lessons learned practices. It commenced by developing a better understanding of how learning is achieved on construction projects. This was supplemented by data obtained via a questionnaire survey, interviews with those responsible for implementing lessons learned and focus groups to understand the needs of site-based personnel. 
The results highlighted a disparity between the goals and outcomes of the populations surveyed. This emphasised the differing needs of each group, the lack of value attributed to the lessons collected and lack of transparency in what happens to the lessons collected.

The results also highlighted the limited use of KM systems and where evident, an ad hoc approach was adopted. Adoption was driven on the potential of the system to 'fix' problems and deliver definite, quantifiable business benefits that stretch across the organisation. This demonstrates a blinkered perspective where there is an expectation that a system should yield business benefits, because an investment is made. But, implementation of any system should be driven by a strategic business need (i.e. learning) that adopts a holistic perspective which considers the implications to the project processes, tools, and people. This view is consistent with that of other studies such as those by Peansupap and Walker, 2006 and Ruikar, et al., 2007 which suggest that organisations should closely manage their KM system initiative decision-making and implementation using pilot studies and a reflective learning approach to maximise advantages from lessons learned. These studies emphasise that technology deployment primarily concerns peoplerelated issues of effective change management, knowledge transfer and leadership by a champion and adoption team to sell benefits and support users.

To improve current practice, a flexible practical approach is needed and the outputs from the study are designed to address this. The recommendation takes the form of a Project Learning Roadmap. The Roadmap looks at addressing the five elements of Needs Identification, Process and Tools, Content and Format, Repository, Communication and Dissemination and Review. These will enable individual organisations to develop their own solutions tailored to take into account the differing stakeholder's needs. Further work 
is needed in the form of industry pilot projects to test the approach and further refine the implementation guide.

\section{References}

Al-Ghassani, A. M., 2003. Improving the structural design process: A knowledge management approach, $\mathrm{PhD}$ thesis, Department of Civil and Building Engineering, Loughborough University, UK.

Anbari, F.T., Carayannis, E.G. and Voetsch, R.J., 2008. Post-project reviews as a key project management competence, Technovation, 28, 633-643.

Argyris, C., 1992. On Organizational Learning, $2^{\text {nd }}$ ed, Blackwell, Oxford.

Carrillo, P., Oluikpe, P., Harding, J, Anumba C., 2007. Extracting Knowledge from Post Project Reviews, Work Package 2, Loughborough University, Internal Report.

Carrillo, P.M. Choudhary, A. K., J. A. Harding, Oluikpe, P., 2011. Knowledge Discovery from Post Project Reviews, Construction Management and Economics, 29(7), 713723.

Carrillo, P.M., 2004. Managing Knowledge: Lessons from the Oil and Gas Sector, Construction Management and Economics, 22(6), 631-642.

Carrillo, P.M., 2005. Lessons Learned Practices in the Engineering, Procurement and Construction Sector. Journal of Engineering, Construction and Architectural Management, 12(3), 236-250.

Chen, L. and Mohamed, S., 2010. The strategic importance of tacit knowledge management activities in construction. Construction Innovation: Information, Process, Management, 10(2), 138-163. 
Collinson, C. and Parcell, G., 2001. Learning to Fly., Capstone Publishing Limited, Oxford.

Cresswell, J.W., 2009. Research Design: Qualitative, quantitative, and mixed methods approaches, California: Sage.

Disterer, G., 2002. Management of Project Knowledge and Experiences. Journal of Knowledge Management, 6(5), 512-520.

Easterby-Smith, M. Crossan, M. and Nicolini, D., 2000. Organization learning: Debates past, present and future. Journal of Management Studies, 37(6), 783-796.

Egbu, C., Kurul, E., Quintas, P. and Hutchinson, V., 2003. Knowledge production, resources and capabilities in the construction industry. Available at http://www.knowledgemanagement.uk.net.

Fellows, R. and Liu, A. ,2003. Research Methods for Construction, Blackwell Publishing, Oxford.

Fuller P. A., Dainty A.R.J. and Thorpe A., 2011. Improving Project learning - a new approach to lessons learnt, International Journal Managing Projects in Business, 4(1), 118-136.

Garon, S., 2006. Space project management lessons learned: a powerful tool for success. Journal of Knowledge Management, 10(2), 103-112.

Gibson, G.E., Caldas, C.H., Yohe, A.M. and Weerasooriya, R., 2007. An Analysis of Lessons Learned Programs in the Construction Industry, Second Edition, Construction Industry Institute, Texas.

Graham, B. and Thomas, K., 2008. Building Knowledge - Developing a Grounded Theory of Knowledge Management for Construction. The Electronic Journal of Business Research Methods, 6(2), $115-122$. 
Highway Agency, 2012. Capability Assessment Toolkit. Available at http://www.highways.gov.uk/business/11999.aspx. Last viewed 04/04/12.

IDeA, 2008. Knowledge management tools and techniques, Available at http://www.idea.gov.uk/idk/aio/8595069, last accessed on 03/04/12.

Julian, J., 2008. How Project Management Office Leaders Facilitate Cross-Project Learning and Continuous Improvement. Project Management Journal, 39(3), 43-58. Lave, J. and Wenger, E., 1991. Situated Learning: Legitimate Peripheral Participation, Cambridge University Press, Cambridge.

Liker, J., 2003. The Toyota Way: 14 Management Principles from the World's Greatest Manufacturer, McGraw-Hill.

Lindner, F. and Wald, A., 2011. Success factors of knowledge management in temporary organizations, International Journal of Project Management, 29(7), 877-888.

McDermott, R. and O'Dell, C. 2001. Overcoming cultural barriers to sharing knowledge. Journal of Knowledge Management, 5(1), 76-85.

New Civil Engineer, 2010. 2010 New Civil Engineer Contractors' File, New Civil Engineers, London.

Nonaka, I. and Takeuchi, H., 1995. The Knowledge Creating Company: How Japanese Companies Create the Dynamics of Innovation, Oxford University Press, New York. O’Dell, C. and Grayson, C.J., 1998. If Only We Knew What We Knew: Identiifcation and Transfer of Internal Best Practices. California Management Review, 40(3), 154-174. Paranagamage, P., Carrillo, P., Ruikar, K. and Fuller, P., 2012. Lessons Learned Practices in the UK Construction Sector: Current Practice and Proposed Improvements Engineering Project Organization Journal, September, 1-15.

Patton, M.Q., 2001. Evaluation, Knowledge Management, Best Practices, and High Quality Lessons Learned, American Journal of Evaluation, 22(3), 329-336. 
Peansupap.V and Walker D.H.T., 2006. Information Communication Technology (ICT) Implementation Constraints: A Construction Industry Perspective. Engineering Construction and Architectural Management, 13(4), 364-379.

Pinto, J.K. and Prescott, J., 1990. Planning and Tactical Factors in The Project Implementation Process. Journal of Management Studies, 27(3), 305-327.

Polyani, M., 1966. The Tacit Dimension, Doubleday and Company, New York.

Quintas, P. Lefrere, P. and Jones, G. (1997) Knowledge Management: A Strategic Agenda. Long Range Planning, 30(3), 385-391.

Robinson, H.S., Carrillo, P.M., Anumba, C.J. and Al-Ghassani, A.M., 2005. Knowledge Management Practices in Large Construction Organisations, Engineering. Construction and Architectural Management, 12(5), 431-445.

Ruggles, R., 1997. Knowledge Management Tools. Butterworth-Heineman, Newton.

Ruikar, K., Anumba, C.J. and Egbu, C., 2007. Integrated use of technologies and techniques for construction knowledge management. Knowledge Management Research and Practice, 5(4), 297-311.

Schindler S, M. and Eppler, M. J., 2003. Harvesting project knowledge: a review of project learning methods and success factors. International Journal of Project Management, 21, 219-228.

Scott, S. and Harris, R., 1998. A methodology for generating feedback in the construction industry. The Learning Organization, 5(3), 121-127.

Secchi, P., Ciaschi, R. and Spence, D., 1999. A Concept for an ESA lessons learned system. Proceedings of Alerts and LL: An Effective way to prevent failures ad problems. Tech. Rep. WPP-167, Noordwijk, The Netherlands, pp. 57-61.

Seranatne, P., and Sexton, M., 2009. Role of knowledge in managing construction project change Engineering, Construction and Architectural Management, 16(2), 186-200. 
Shook, J., 2008. Managing to Learn: Using the A3 management process, Lean Enterprises Institute, Cambridge, MA.

Sinclair, S., 2012. Opinion Piece-Current Processes for Capturing Feedback. In Project, April, 8-9.

Szulanski, G. 1996. Exploring Internal Stickiness: Impediments to the Transfer of Best Practice within the Firm. Strategic Management Journal, 17, 27-43.

Tsoukas, H., 1996. The firm as a distributed knowledge system: a constructionist approach. Strategic Management Journal, 17, 11-25.

Udeaja, C., Kamara, J.M., Carrillo, P.M., Anumba, C.J., Bouchlaghem, N.M. and Tan, H.C., 2006. Live Capture and Reuse of Construction Project Knowledge: Capri.Net Approach. Proceedings International Conference on Construction Culture, Innovation and Management (CCIM), M. Dulaimi (ed.), Dubai, UAE, 26 November, 813-823.

Von Krogh, G., Nonaka, I. and Rechsteiner, L., 2012. Leadership in Organizational Knowledge Creation: A Review and Framework. Journal of Management Studies, 49(1), 240-277.

Weber, R., Aha, D.W. and Becerra-Fernandez, I., 2001. Intelligent Lessons Learned Systems, 20(1), 1-38.

Weiser, M., and Morrison, J., 1998. Project Memory: Information management for Project teams. Journal of Management Information Systems, 14(4), 149-166.

Wenger, E., 2004. Knowledge management as a doughnut: Shaping your knowledge strategy through communities of practice. Ivey Business Journal, January/February, $1-9$

Wiewiora, A., Trigunarsyah, B.and Murphy, G. and Liang, C., 2009. Barriers to effective knowledge transfer in project-based organisations. In: Proceedings of the 2009 
International Conference on Global Innovation in Construction, 13-16 September, Holywell Park, Loughborough University.

Williams, T., 2004. Identifying the hard lessons from projects - easily. International Journal of Project Management, 22(4), 272-279.

Williams, T., 2008. How Do Organizations Learn Lessons From Projects-And Do They? IEEE Transactions on Engineering Management, 55(2), 248-266.

Yin, R.K., 2009. Case study research: Design and methods, Sage Publications, California. 
Table 1: Interviewees’ Positions and Size of Organisation

\begin{tabular}{|c|l|c|}
\hline Company & Position & Approximate Annual Turnover (£M) \\
\hline A & Business Systems Manager & 1000 \\
\hline B & Chief Engineer & 1700 \\
\hline C & Head of Value & 7600 \\
\hline D & Head of Business Development and IT & 100 \\
\hline E & Business Development Director & 10000 \\
\hline F & Knowledge Manager & 1600 \\
\hline G & Associate Director & 900 \\
\hline H & Managing Director & 100 \\
\hline I & Business Development Director & 1200 \\
\hline
\end{tabular}


Table 2: Explicit vs. Tacit Knowledge Sharing Tools

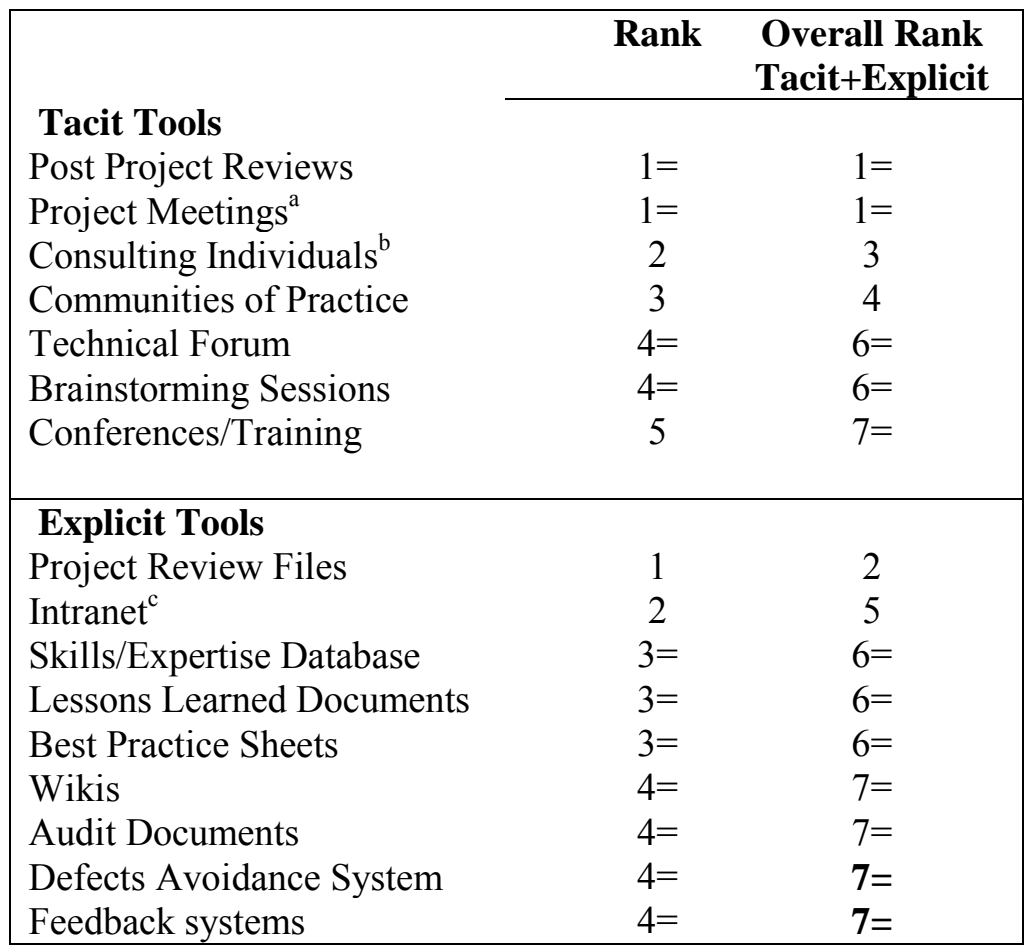

a Refers to a range of meetings occurring throughout the life cycle of the project e.g. Design, Bid team, Post Tender, Pre-start, Weekly progress/site meetings

b Refers to one-to-one communication e.g. telephone conversations, face-to-face meetings, email correspondence, video conferencing, webinars

c Refers to specific websites e.g. knowledge banks, guidance documents, standard forms, databases 
Table 3: Summary of Data Collected

\begin{tabular}{|c|c|c|c|}
\hline & Questionnaires & Interviews & Focus Groups \\
\hline Needs & $\begin{array}{l}\text { Number of reasons for } \\
\text { collecting lessons } \\
\text { learned identified } \\
\text { Different requirements } \\
\text { based on position }\end{array}$ & $\begin{array}{l}\text { Lack of perceived value } \\
\text { Internal competition a } \\
\text { barrier }\end{array}$ & $\begin{array}{l}\text { Little value added from } \\
\text { lessons }\end{array}$ \\
\hline $\begin{array}{l}\text { Process and } \\
\text { Tools }\end{array}$ & $\begin{array}{l}\text { Range of tools used (ICT } \\
\text { and non-ICT) }\end{array}$ & $\begin{array}{l}\text { Needs to cover tacit and } \\
\text { explicit knowledge } \\
\text { Face to face interaction } \\
\text { important } \\
\text { Clearer processes needed } \\
\text { Legal issue a barrier }\end{array}$ & $\begin{array}{l}\text { Need to support } \\
\text { personal interactions } \\
\text { Lack of understanding } \\
\text { of range of tools } \\
\text { available } \\
\text { Focus on process rather } \\
\text { than outcome } \\
\text { Corporate tools not } \\
\text { always useful }\end{array}$ \\
\hline $\begin{array}{l}\text { Content and } \\
\text { Format }\end{array}$ & $\begin{array}{l}\text { Various types of lessons } \\
\text { needed dependent on } \\
\text { project stage }\end{array}$ & $\begin{array}{l}\text { Too much duplication of } \\
\text { lessons in different } \\
\text { formats }\end{array}$ & $\begin{array}{l}\text { Corporate requirements } \\
\text { not matched with site } \\
\text { needs }\end{array}$ \\
\hline Repository & $\begin{array}{l}\text { Range of storage media } \\
\text { used }\end{array}$ & $\begin{array}{l}\text { Combination of paper } \\
\text { and electronic } \\
\text { documents }\end{array}$ & $\begin{array}{l}\text { Intranet considered a } \\
\text { black hole with too } \\
\text { much data } \\
\text { Difficult to retrieve } \\
\text { information easily }\end{array}$ \\
\hline $\begin{array}{l}\text { Communication } \\
\text { and } \\
\text { Dissemination }\end{array}$ & $\begin{array}{l}\text { Access to lessons an } \\
\text { important issue }\end{array}$ & $\begin{array}{l}\text { Communication of } \\
\text { lessons need to be } \\
\text { addressed }\end{array}$ & $\begin{array}{l}\text { Lack of awareness of } \\
\text { outcome of data } \\
\text { collected for lessons } \\
\text { learned } \\
\text { Lack of communication } \\
\text { between office and } \\
\text { site staff } \\
\text { Lack of communication } \\
\text { between sites }\end{array}$ \\
\hline
\end{tabular}


Table 4: Excerpts of Checklist for Project Learning Roadmap

\begin{tabular}{|c|c|c|c|}
\hline $\begin{array}{l}\text { Checklist } 1 \\
\text { Needs Identification }\end{array}$ & Sample Areas & Corporate Needs & Project Needs \\
\hline & & $\begin{array}{l}\text { Health \& Safety } \\
\text { Construction programmes } \\
\text { Procurement issues }\end{array}$ & $\begin{array}{l}\text { Construction Methods } \\
\text { Site Logistics } \\
\text { Environmental issues }\end{array}$ \\
\hline \multirow[t]{2}{*}{$\begin{array}{l}\text { Checklist } 2 \\
\text { Processes and Tools }\end{array}$} & Sample Tools Available & SMES & Large Organisations \\
\hline & $\begin{array}{l}\text { Post Project Reviews } \\
\text { Community of Practice } \\
\text { Electronic Discussion } \\
\text { Document Management } \\
\quad \text { Systems } \\
\text { Knowledge Mapping Tools } \\
\text { Project Databases } \\
\text { Project Extranets } \\
\text { Skills Yellow Pages } \\
\text { Text Mining Tools } \\
\text { Video Conferencing } \\
\text { Workshops }\end{array}$ & $\begin{array}{l}\mathrm{X} \\
\mathrm{X} \\
\mathrm{X} \\
\mathrm{X}\end{array}$ & $\begin{array}{l}\mathrm{X} \\
\mathrm{X} \\
\mathrm{X} \\
\mathrm{X} \\
\mathrm{X} \\
\mathrm{X} \\
\mathrm{X} \\
\mathrm{X} \\
\mathrm{X} \\
\mathrm{X} \\
\mathrm{X} \\
\mathrm{X}\end{array}$ \\
\hline \multirow[t]{2}{*}{$\begin{array}{l}\text { Checklist } 3 \\
\text { Content and Format }\end{array}$} & Example Report Format & SMES & Large Organisations \\
\hline & & Toyota A3 Report & Toyota A3 Report \\
\hline \multirow[t]{2}{*}{$\begin{array}{l}\text { Checklist } 4 \\
\text { Repository }\end{array}$} & $\begin{array}{l}\text { Example of Storage and } \\
\text { Retrieval Mechanisms }\end{array}$ & SMEs & Large Organisations \\
\hline & $\begin{array}{l}\text { Database } \\
\text { Intranet } \\
\text { Indexing and keywords }\end{array}$ & $\begin{array}{l}\mathrm{X} \\
\mathrm{X}\end{array}$ & $\begin{array}{l}X \\
X\end{array}$ \\
\hline \multirow[t]{2}{*}{$\begin{array}{l}\text { Checklist } 5 \\
\text { Communication and } \\
\text { Dissemination } \\
\end{array}$} & $\begin{array}{l}\text { Example Dissemination } \\
\text { Mechanisms }\end{array}$ & SMEs & Large Organisations \\
\hline & $\begin{array}{l}\text { Intranet } \\
\text { Web-forums } \\
\text { Wikis } \\
\text { Booklets } \\
\text { Newsletters } \\
\text { Alerts }\end{array}$ & $\begin{array}{l}\mathrm{X} \\
\mathrm{X} \\
\\
\mathrm{X} \\
\mathrm{X}\end{array}$ & $\begin{array}{l}X \\
X \\
X \\
X \\
X \\
X\end{array}$ \\
\hline \multirow[t]{2}{*}{$\begin{array}{l}\text { Checklist } 6 \\
\text { Review }\end{array}$} & Sample Review Mechanisms & SMEs & Large Organisations \\
\hline & & Feedback & Company metrics \\
\hline
\end{tabular}




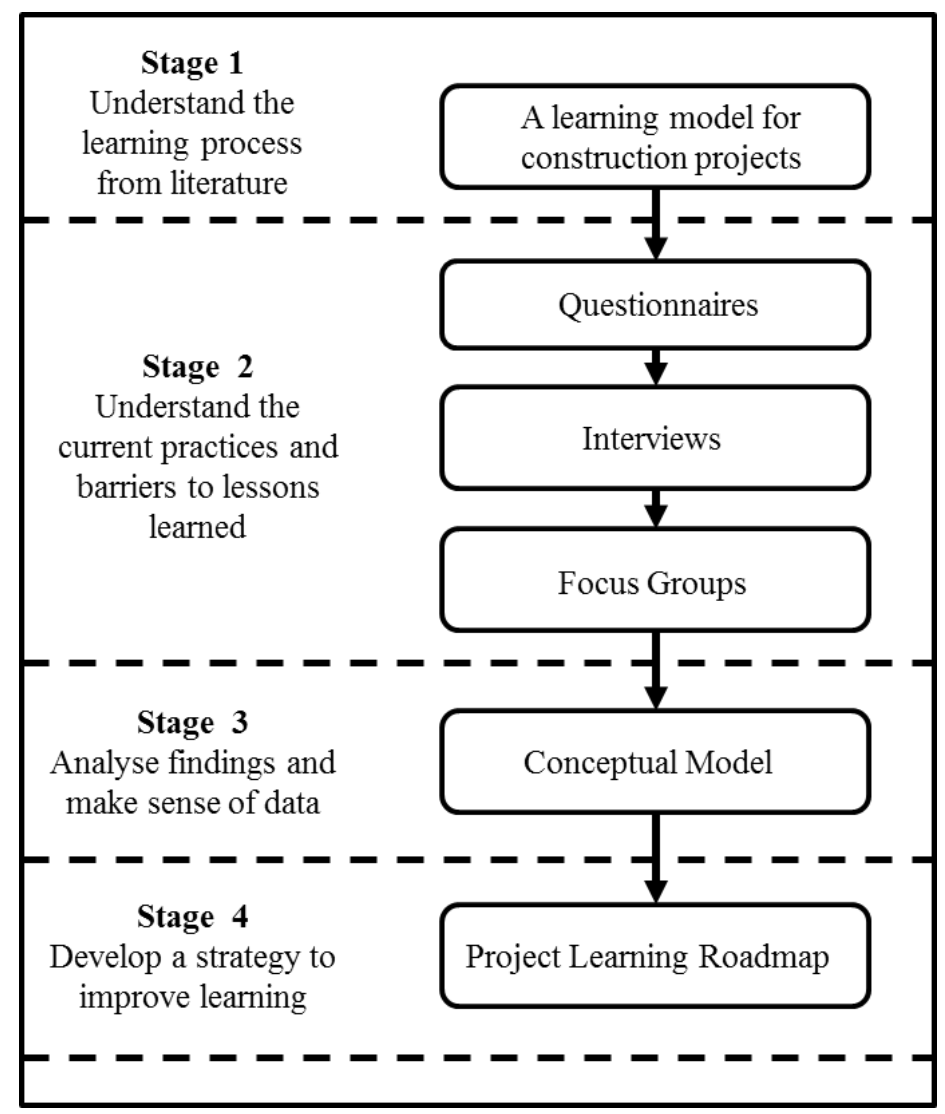

Figure 1: Research Stages 


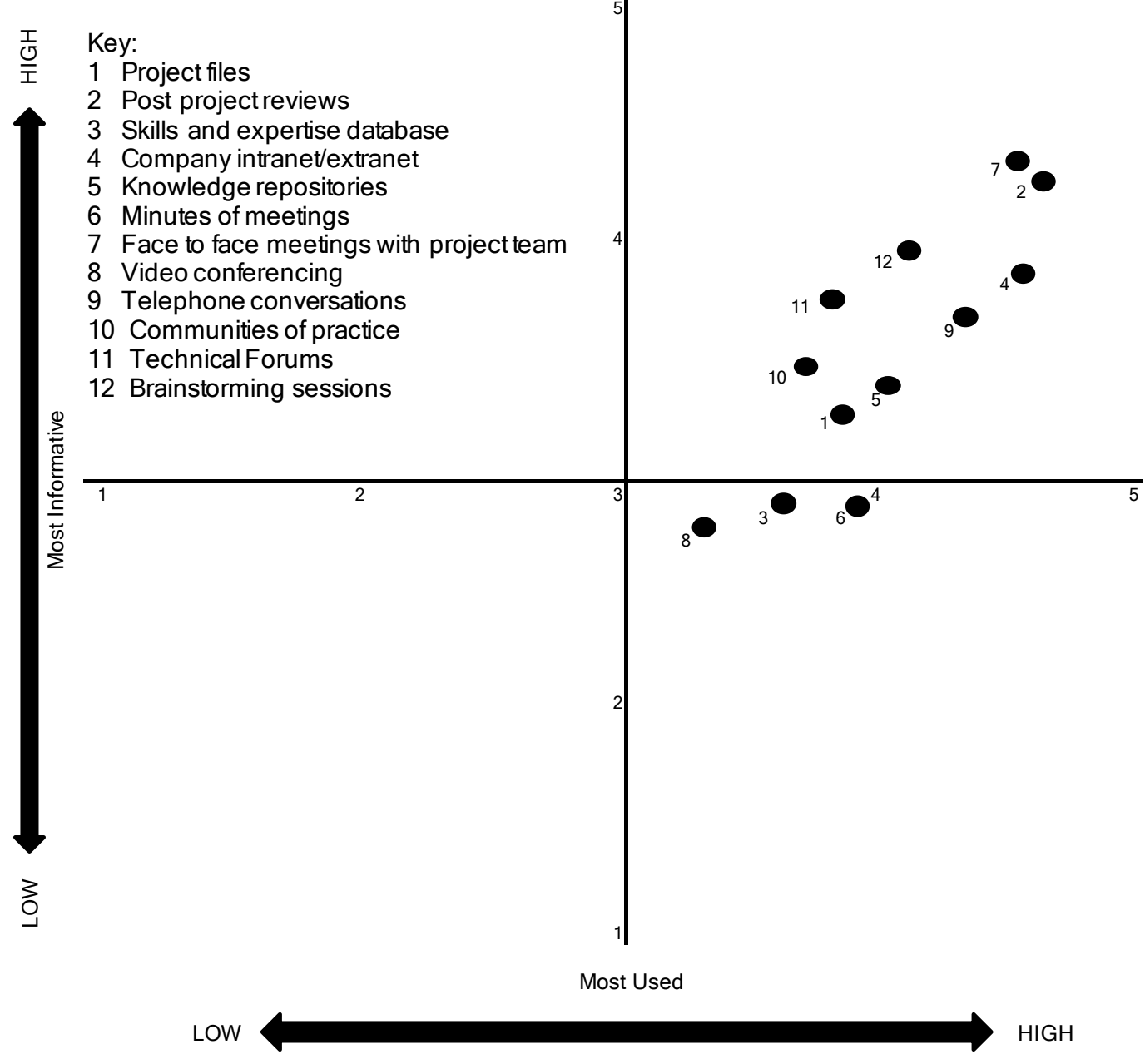

Figure 2: Commonly Used Practices in Relation to Most Informative Practices 


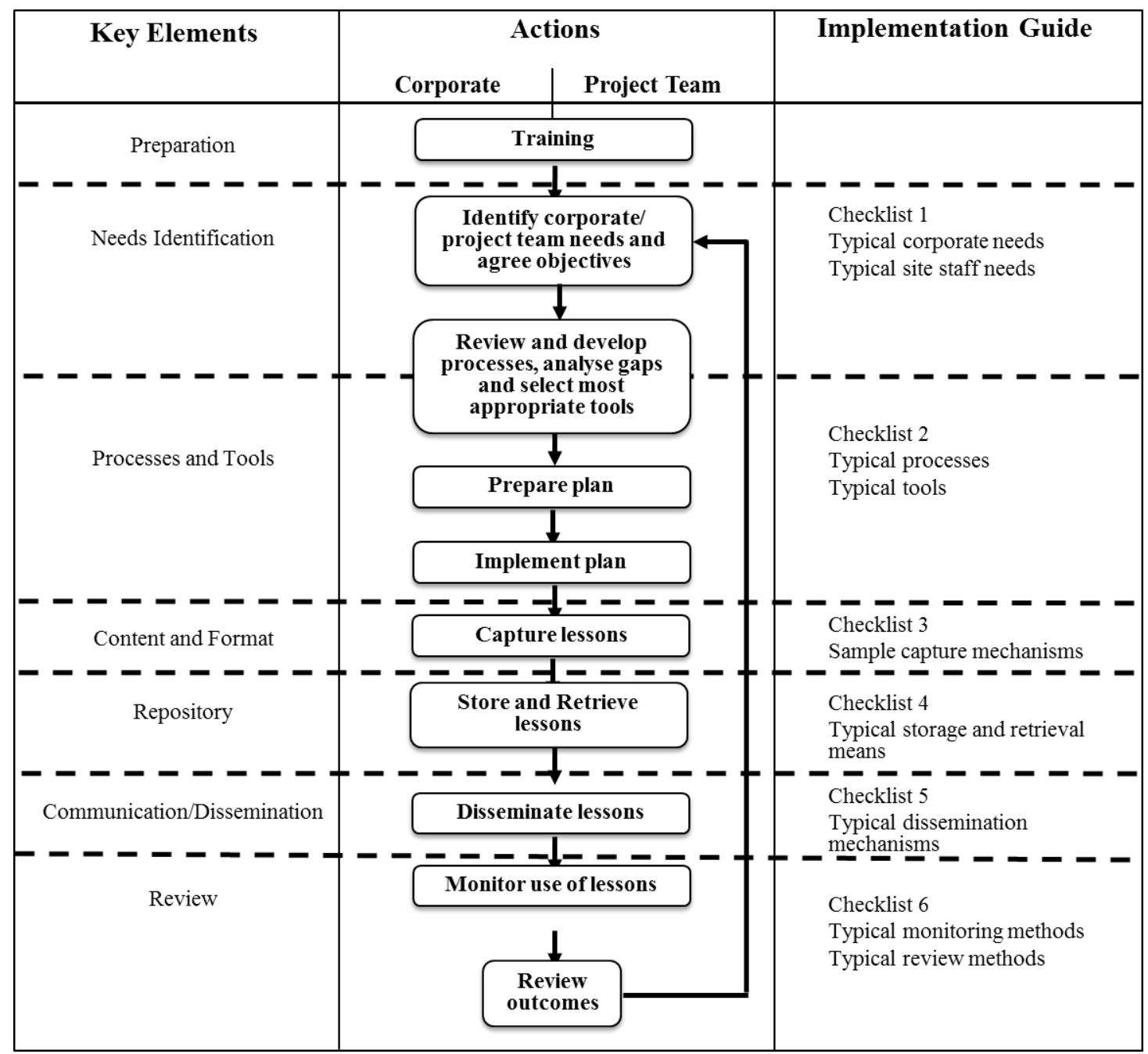

Figure 3: Project Learning Roadmap 